\title{
Research Paper: \\ The Veracity of Traumatic Spinal Cord and Related Nerve Injuries in a Developing Country: The Cyprus Case Study
}

Eleni Tsianaka ${ }^{1^{*}}$ (D) Nikolay Konovalov ${ }^{1}$, Andronikos Spyrou $^{2}$, Alexander Potapov ${ }^{3}$, Leonid Lichterman ${ }^{3}$, Michael Spyrou $^{4}$

1. Department of Spine Neurosurgery, Federal State Autonomous Institution, N. N. Burdenko National Medical Research Center for Neurosurgery, Russian Federation Ministry of Health, Moscow, Russia

2. Federal State Autonomous Educational Institution, N. N. Burdenko National Medical Research Center for Neurosurgery, Russian Federation Ministry of Health, Moscow, Russia

3. Department of Neurotraumatology, Federal State Autonomous Educational Institution, N. N. Burdenko National Medical Research Center for Neurosurgery, Russian Federation Ministry of Health, Moscow, Russia

4. Department of Neurosurgery, Ygia Private Hospital, Limassol, Cyprus

\begin{tabular}{|l|l|l|l}
$\begin{array}{c}\text { Use yur device to scan } \\
\text { and read the article online }\end{array}$ & $\begin{array}{l}\text { Crtation: Tsianaka E, Konovalov N, Spyrou A, Potapov A, Lichterman L, Spyrou M. The Veracity of Traumatic Spinal Cord and } \\
\text { Related Nerve Injuries in a Developing Country: The Cyprus Case Study. Iran J Neurosurg. 2018; 4(2):109-116. http://dx.doi. } \\
\text { org/10.32598/irjns.4.2.109 }\end{array}$ \\
doi: : http://dx.doi.org/10.32598/irjns.4.2.109
\end{tabular}

\section{(c) (1) (s)}

Funding: See Page 114

Article info:

Received: 20 November 2017

Accepted: 23 February 2018

Available Online: 01 April 2018

Keywords:

Trauma, Spinal cord, Nerves, Injuries, Spine, Biostatistics

\section{A B S T RACT}

Background and Aim: This is a retrospective epidemiological study, based on ICD-10 system, using statistical data from the Cyprus Statistical Service official archives. To estimate the spinal cord injury incidence and its characteristics like gender preference and hospitalization, in Cyprus people, over a 10-year period of time. The study investigated cases that have occurred within the territory of the Republic of Cyprus.

Methods and Materials/Patients: The data from the Cyprus Statistical Service official archives were reviewed based upon the ICD-10 searching, using annual reports, from 2005 to 2014. The extracted information included the number of hospitalized patients, using ICD-10 codes S14, S24 and S34, sex and days of hospitalization. In order to report the incidence rates, we used the Cyprus Statistical Service official demographic data.

Results: The Mean Spinal Cord and the related Nerves Injury ( $\mathrm{SCl}$ and $\mathrm{NI}$ ) incidence were calculated to be $0.24 \%$. The Mean $\mathrm{SCl}$ and $\mathrm{NI}$ male incidence rate was $0.158 \%$. The mean SCl and $\mathrm{NI}$ female incidence rate was $0.076 \%$. There were 2.8 days of hospitalization per every $\mathrm{SCl}$ and $\mathrm{NI}$ patient per year.

Conclusion: Based on the study results, it seems advisable to have a National Spine and Spinal Cord Injury registry, in order that different parameters be correlated in a more effective way. The study highlights the need for a well-organized trauma and rehabilitation center which would be of great benefit for the health system of the country. Furthermore, this information can be useful in future health economic studies related to the $\mathrm{SCl}$ and $\mathrm{NI}$.

\section{* Corresponding Author:}

Eleni Tsianaka, MD

Address: Department of Spine Neurosurgery, Federal State Autonomous Institution, N. N. Burdenko National Medical Research Center for Neurosurgery, Russian Federation Ministry of Health, Moscow, Russia

Tel: +7 (965) 66484779

E-mail: ariadniq@yahoo.gr 


\section{Highlights}

- Spinal cord injury and nerve-related injuries incidence (\%) ranged between $0.15 \%$ in 2012 and $0.31 \%$ in 2007 .

\section{Plain Language Summary}

Spinal cord injury is an event leading to personal, emotional and physical stress. That problem affects patients, their families, all sectors of the health care system (from primary health care to rehabilitation) and both the employment and pension schemes in each country. Injuries can occur at any spine level. Spinal cord injuries can be complete or incomplete thus causing problems in mobility and or sensation of the injured person; conditions that can be fatal in some cases. Specialized trauma centers, including spine trauma units, have been developed in countries with efficient health systems. Within such health systems, the specialized rehabilitation centers are an integral part of the system, prioritizing the patient's well-being. Subsequently, the system saves a lot of money which can then be used for other purposes.

In our study, we used all available statistical information from the official government archives of Cyprus, in order to investigate the spinal cord injury incidence and its structural characteristics in relation to sex and hospitalization in this country, over a 10-year period. The Spinal Cord and the related Nerves Injuries (SCI \& NI) were found to be $0.24 \%$ of the total population. They were $0.158 \%$ for men and $0.076 \%$ for women, respectively. The mean stay in the hospital for these patients was 2.8 days.

This study highlighted the need for a National Spine and Spinal Cord Injury registry in order that different parameters be correlated in a more effective way. The study highlights the need for a well-organized trauma center and a rehabilitation center which would benefit the country's health system a lot. Furthermore, this information can be useful in future health economic studies related to the $\mathrm{SCl}$ and $\mathrm{NI}$ and could pave the way for further research.

\section{Introduction}

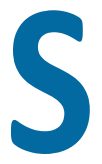

pinal cord injury is usually followed by personal, emotional, and physical stress. This injury affects not only patients, but also their families, all sectors of the health care system (from primary health care to rehabilitation) and finally the employed and the pension system in each country [1-3]. These outcomes highlights the importance of the situation. Injury can occur at any spine level. Spinal cord injuries can be complete or incomplete, presenting with motor and/ or sensory disorders; conditions that can be fatal in some cases [4].

The severity of the problem requires responsible behavior from the state. Specialized trauma centers, including spine trauma units, have been already established in countries with efficient health systems. Within such health systems, the specialized rehabilitation centers are an integral part of the system, prioritizing the patient's well-being. Subsequently, the system acquires economic benefits. Different parameters contribute to how spinal cord and related nerve injuries
(SCl \& NI) affect the quality of life of a patient. Most of these parameters are specific to the country where the injury occurs.

Generally, the specifications of a developing country should not be used in planning the health system strategy and applied to another country, because various parameters can affect the health system's environment and behavior [5-7]. However, the individual study of $\mathrm{SCl}$ and $\mathrm{NI}$ in every country can customized the preventing measures in that health system structure. The study aims to estimate the $\mathrm{SCl}$ and $\mathrm{NI}$ incidence and its characteristics in terms of sex, and days of hospitalization, and characteristics of Cyprus individuals, over a 10-year period of time. Our study intends to help the Cyprus National Health System to pace in the right direction by providing the necessary information.

\section{Materials \& Methods/Patients}

This is a retrospective study, which investigated the relevant cases within the Republic of Cyprus. The research was performed using statistical data from the Cyprus Statistical Service archives [8, 9]. The annual 
analytical reports from the Cyprus Statistical Service, have reliably and continuously been published by the Republic of Cyprus since 1980. The collected data were categorized based on the ICD-10 searching, using annual reports, from 2005 to 2014 . The data included all trauma patients (including only initial admission for every patient) experienced $\mathrm{SCl}$ and/or $\mathrm{NI}$, from January 2005 to December 2014 (10-year period) and have been hospitalized at public or private hospitals of the Republic of Cyprus.

For that purpose, the injured cases based on ICD-10 codes were identified: S14 (injury of nerves and spinal cord at neck level), S24 (injury of nerves and spinal cord at thorax level) and S34 (injury of lumbar and sacral spinal cord and nerves at abdomen lower back and pelvis level) [10]. The study excluded congenital spinal defects and spinal cord injuries (ICD-10 code $\mathrm{P} 11.5)$. Where cases were identified as using the ICD-9 system, we translated them into corresponding ICD-10 code $[10,11]$.

The extracted information included a number of hospitalized patients, using the above codes, sex and days of hospitalization. In order to report the rates, we used the Cyprus Statistical Service demographic data $[8,12]$. The collected data included a total of both male and female population in each year. The statistical analysis was performed in SPSS V. 22.

\section{Results}

The total population in the Cyprus Republic has increased from 766400 in 2005 to 865900 in 2012, with a mild decline after that year (847000 in 2014). After we conducted a study based on hospitalized $\mathrm{SCl}$ and $\mathrm{NI}$ patients, in all of the Republic of Cyprus hospitals (public and private), during a 10-year period of time (2005-2014), we found $\mathrm{SCl}$ and $\mathrm{NI}$ patients range between 1309 and 2446 per year, with a mean \pm SD of $1911.00 \pm 366.023$ per year. The rate of $\mathrm{SCl}$ and $\mathrm{NI}$ incidence (\%) ranged between $0.15 \%$ in 2012 and $0.31 \%$ in 2007 in the total population. The Mean \pm SD SCl and NI incidence was calculated as $0.24 \pm 0.05$ (Tables 1 and 2).

The male and female incidence rates of the $\$ 14 / 24 / 34$ ICD-10 group ranged from $0.10 \%$ to $0.21 \%$ (Mean: $0.158 \%$ ) for male cases and from $0.05 \%$ to $0.10 \%$, (Mean: $0.076 \%$ ) for the female cases (Table 2). Another factor which we studied, was the days of hospitalization; 2012 had the minimum days of hospitalization for S14/24/34 patients (3313 days) whereas 2007 had the maximum days of hospitalization of our group patients as 8004 days (Table 1). The mean hospitalization days per year of $\mathrm{SCl}$ and $\mathrm{NI}$ patients were 420.9 days (Table 2 ).

\section{Discussion}

Spinal cord trauma has serious consequences for the patient, his/her family and the society. This huge bur-

Table 1. S14/24/34 incidence, gender incidence and days of hospitalization per year (years 2005-2014)

\begin{tabular}{|c|c|c|c|c|c|c|c|c|}
\hline \multirow[b]{2}{*}{ Year } & \multirow{2}{*}{$\begin{array}{c}\text { Total } \\
\text { Population }\end{array}$} & \multirow{2}{*}{$\begin{array}{c}\text { S14/24/34 } \\
\text { Patients }\end{array}$} & \multirow{2}{*}{$\begin{array}{c}\text { S14/24/34 } \\
\text { Male }\end{array}$} & \multirow{2}{*}{$\begin{array}{c}\text { S14/24/34 } \\
\text { Female }\end{array}$} & \multicolumn{3}{|c|}{ Incidence (\%) } & \multirow{2}{*}{$\begin{array}{c}\text { Days of } \\
\text { Hospitaliza- } \\
\text { tion }\end{array}$} \\
\hline & & & & & S14/24/34 & $\begin{array}{c}\text { S14/24/34 } \\
\text { Male }\end{array}$ & $\begin{array}{c}\text { S14/24/34 } \\
\text { Female }\end{array}$ & \\
\hline 2005 & 766400 & 2136 & 1424 & 712 & 0.28 & 0.19 & 0.09 & 6532 \\
\hline 2006 & 778700 & 2292 & 1559 & 733 & 0.30 & 0.20 & 0.09 & 6047 \\
\hline 2007 & 789300 & 2446 & 1655 & 791 & 0.31 & 0.21 & 0.10 & 8004 \\
\hline 2008 & 796900 & 2150 & 1448 & 702 & 0.27 & 0.18 & 0.09 & 6758 \\
\hline 2009 & 803200 & 1718 & 1188 & 530 & 0.21 & 0.15 & 0.07 & 5496 \\
\hline 2010 & 839800 & 1993 & 1367 & 626 & 0.24 & 0.16 & 0.07 & 4742 \\
\hline 2011 & 862000 & 1456 & 944 & 512 & 0.17 & 0.11 & 0.06 & 3527 \\
\hline 2012 & 865900 & 1309 & 851 & 458 & 0.15 & 0.10 & 0.05 & 3313 \\
\hline 2013 & 858000 & 1681 & 1138 & 543 & 0.20 & 0.13 & 0.06 & 4393 \\
\hline 2014 & 847000 & 1929 & 1287 & 642 & 0.23 & 0.15 & 0.08 & 5397 \\
\hline
\end{tabular}


Table 2. SCl and NI patients incidence rates and days of hospitalization

\begin{tabular}{|c|c|c|c|c|c|}
\hline \multicolumn{2}{|c|}{ Characteristics } & \multirow{2}{*}{$\frac{\mathbf{N}}{10}$} & \multirow{2}{*}{$\begin{array}{l}\text { Min } \\
0.15\end{array}$} & \multirow{2}{*}{$\begin{array}{l}\text { Max } \\
0.31\end{array}$} & \multirow{2}{*}{$\frac{\text { Mean } \pm S D}{0.2360 \pm 0.05420}$} \\
\hline $\begin{array}{l}\mathrm{SCl} \& \mathrm{NI} \text { patients } \\
\text { Incidence }\end{array}$ & S14/24/34 incidence (\%) & & & & \\
\hline \multirow{2}{*}{$\begin{array}{l}\mathrm{SCI} \& \mathrm{NI} \text { patients gender } \\
\text { Incidence }\end{array}$} & S14/24/34 Male incidence (\%) & 10 & 0.10 & 0.21 & $0.1580 \pm 0.03736$ \\
\hline & S 14/24/34 Female incidence (\%) & 10 & 0.05 & 0.10 & $0.0760 \pm 0.01647$ \\
\hline \multirow{2}{*}{$\begin{array}{l}\mathrm{SCl} \& \mathrm{NI} \text { patients days of } \\
\text { hospitalization }\end{array}$} & Hospitalization S14/24/34 (days) & 10 & 3313 & 8004 & $5420.90 \pm 1477.256$ \\
\hline & Valid N (listwise) & 10 & & & \\
\hline
\end{tabular}

den can be both psychologically and economically [13]. The challenge for all physicians is to make the patient as independent as possible. Prevention is the area where society must indulge on to decrease the incidence of spinal cord injury.

To accomplish this objective, the incidence of spinal cord trauma has to be determined first and then be correlated with various variables. The study of spinal cord injury related to whole country demographics and based on the ICD-10 classification would be of great interest. Our study presents an interesting analysis of $\mathrm{SCl}$ and $\mathrm{NI}$ characteristics, based on the official demographic data of the country (Republic of Cyprus). Nowadays, in Cyprus, $80 \%$ of the health system services are provided by the public sector and $20 \%$ by the private sector. The patients' distribution follows the same pattern. However in Cyprus, the doctor's distribution is the opposite $(80 \%$ of them are employed in the private hospitals and only $20 \%$ in public hospitals).

All kinds of trauma patients are immediately transferred to public hospitals. The majority of them remain in public hospitals and only some of them are transferred to private hospitals, upon the request of the patient or his or her family. All efforts to evaluate and establish a well-organized trauma center with international standards at the present moment has been unsuccessful.

Public hospitals are entrusted with the responsibility of addressing trauma patients. Analyzing the data with regard to the ICD-10 groups, we find that the S14/24/34 incidence in general population is $0.24 \%$, which is considered to be very high, compared with other countries studied. Based on the international published data of developed countries, this rate ranges between 0.01 and 0.13 cases per 1000 people of the general population [14]. Regarding the developing countries, the incidence ranges between 0.021 (Saudi Arabia) and 0.13 (Bulgaria) [7]. In Europe, the spinal cord injury incidence ranges between 0.13 (Bulgaria) and 0.01 (Denmark) [15-23]. According to our results, this incidence is about 2.4 cases per 1000 people of the general population (Table 2). However, in our results (based on ICD-10 coding) the incidence refers not only to spinal cord injury, but to nerves injury too.

The differences in study design (data source, collection and extraction) can explain the different results. Therefore, the inconsistencies in incidence is justified to a certain extent. On the other hand, our results refer to hospitalized patients, unlike the international data, which refer to all spinal cord injury patients. Besides, the Cyprus witnesses a large number of hospitalized patients which might be unnecessary that results in higher cost for the national health care system. Additionally, in some developing countries, low incidence can be related to the high mortality during pre-hospital time [24].

The realization of Advanced Trauma Life Support (ATLS) courses in Cyprus, has minimized prehospital mortality. In Cyprus, all trauma survivors are transferred to public general hospitals, where the vast majority are examined by orthopedics, general surgeons or general practitioners. In Cyprus, there is only one neurosurgical department in a public hospital, so in many cases, other physicians and not neurosurgeons are involved in spine trauma cases, resulting in high hospitalization rates. However, the difference remains huge and that is the reason why we cannot disregard the fact that Cyprus is a left-handdriving country, with overnight entertainment (including alcohol consumption), a lot of motorbikes (due to the small distances between cities), and no public transportation. These might explain the high trauma rates, including spinal cord injuries. The male predisposition has been reported in all studies, but the ratio of the developing 
countries (Mean M:F Ratio: 4.8) is much higher than the developed ones (Mean M:F Ratio: 3-4) [24]. In Cyprus, the ratio shows male predisposition (2:1), but it is lower compared with other developing countries.

This low ratio might be due to protective initiatives against dangerous male activities or rise of women being exposed to danger. Future studies of mechanisms of $\mathrm{SCl}$ and $\mathrm{NI}$ should clarify this issue. Additionally, there is a slight decrease in incidence, in both genders, over the years, probably reflecting to the continuing improvement of living conditions (Table 1). Generally, multipletrauma patients have the worst outcome, in contrast to uncomplicated spine trauma patients [25]. Co-injuries, when not leading to death, complicate the rehabilitation procedure [26-28]. Evidently that leads to longer hospitalization of the patients. According to our data, the hospitalization for $\mathrm{SCl}$ and $\mathrm{NI}$ patients was 420.90 days per year (Table 2). The hospitalized $\mathrm{SCl}$ and $\mathrm{NI}$ patients per year was about 1911 i.e., the corresponding days of hospitalization for every $\mathrm{SCl}$ and $\mathrm{NI}$ patient per year (hospitalization/ patient/ year) was approximately 2.8 days (Table 2 ).

As regards the international data, hospitalization for any pathology is about 4.9 days and for spinal cord injury 19 days [29]. Surprisingly, we discovered that the spinal cord and nerve injury groups have a much shorter hospitalization stay, compared with the international data. The results in this area have high standard deviation which represent great data variation. We suppose that a large number of factors determine the length of hospitalization in these cases, such as clinical presentation, need for operation, management difficulties when they do not fall within clear guidelines, availability of rehabilitation centers and so on.

Once more, we feel the necessity of a well-organized trauma center, with inter-specialization on spine trauma. Moreover, the establishment of a rehabilitation center, where all SCl and $\mathrm{NI}$ patients can be transferred to (after they have been discharged from the hospital) can further decrease the days of hospitalization, gaining resources for the health system of the country.

Despite the numerous advantages of our study (based on national documentation, reliable source of information, long period of study time i.e., ten years, results referring to a whole country), there are still some limitations. The first limitation is the use of ICD-10 system, to collect and categorize the data. It is relatively a rigid system. Using that system, a multiple-trauma patient cannot be well defined within terms of their clinical con- dition. Besides, ICD-10 system provides a poor patient description, because it cannot describe the patient's condition as a whole, but it focuses only on a single dimension diagnosis.

The ICD-10 system is primarily established based on the needs of health economic analysis, not taking into consideration health, social or medical statistical related needs. Our data collection tool was national archives in a retrospective study. Thus, it was impossible to correlate data independently. For example, there was no information about trauma mechanism in these patients that could be of great value. In addition, our study design could not be as flexible as we would have liked it to be, because national statistical records limited the structure of the data.

One can argue that our studied parameters were almost predefined (there was no ability to study and correlate parameters such as age and mortality), so we missed the opportunity to make groups, based on injury level and correlate that with sex, age and mortality rate, which would be important. Furthermore, in official documents, there is no available data about those patients' mortality etiology, clinical condition and outcome after hospital discharge, rehabilitation process or even late mortality. Finally, our study just included hospitalized patients, so we cannot estimate the incidence of mild $\mathrm{SCl}$ and $\mathrm{NI}$, in the patients who did not seek medical help or discharged from the Emergency Department without hospitalization. A national registry for spine trauma patients and a future prospective study with clinical orientation could solve most of these limitations.

\section{Conclusion}

This is an epidemiological study on traumatic $\mathrm{SCl}$ and $\mathrm{NI}$ patients at a country level (Republic of Cyprus), analyzing incidence, gender distribution and hospitalization time, trying to find the $\mathrm{SCl}$ and $\mathrm{NI}$ characteristics, and picturing a general view of the situation. Based on the study results, it seems advisable to have a National Spine and Spinal Cord Injury registry, in order that different parameters be correlated in a more effective way, for example, trauma mechanism with gender predisposition. Obviously, a national Spine and Spinal Cord Injury registry could be a very useful tool to effectively prevent this kind of injuries. That can be a part of a wider health strategy project, given the country has the ability to have resources (human and economic). Moreover, a well-organized trauma center, according to the international standards, would be very helpful to avoid 
unnecessary admissions, minimize hospitalization time and risk of death and disabilities.

All in all, a well-organized rehabilitation center can be of great benefit for the health system. Despite the limitations, our study can be very useful in understanding the spinal cord injuries profile and its basic characteristics to design not only a preventing guide, but also an educational tool for these patients. Furthermore, the results of our study can help the health strategy plan of Cyprus and support future health economic studies (our study is epidemiological, not economic one), related to spine and spinal cord injuries.

\section{Ethical Considerations}

\section{Compliance with ethical guidelines}

It is a biostatistical analysis which didn't involve patients directly.

\section{Funding}

This research did not receive any specific grant from funding agencies in the public, commercial, or not-forprofit sectors.

\section{Authors contributions}

All authors have read and approved the manuscript.

\section{Conflict of interest}

The authors declared no conflict of interest.

\section{Acknowledgements}

The authors thank Aglaia Alexiou (English teachergraduated from the Faculty of English Language and Literature, Aristotle University of Thessaloniki, Greece) for her corrections and assistance on English language.

\section{References}

[1] Dryden DM, Saunders LD, Rowe BH, May LD, Yiannakoulias N, Svenson LW, et al. The epidemiology of traumatic spinal cord injury in Alberta, Canada. Canadian Journal of Neurological Sciences. 2003, 30(2):113-21. [DOI:10.1017/S0317167100053373] [PMID]

[2] Pickett W, Simpson K, Walker J, Brison RJ. Traumatic spinal cord injury in Ontario, Canada. The Journal of Trauma and Acute Care Surgery. 2003, 55(6):1070-6. [DOI:10.1097/01.TA.0000034228.18541.D1] [PMID]
[3] McCammon JR, Ethans K. Spinal cord injury in Manitoba: A provincial epidemiological study. The Journal of Spinal Cord Medicine. 2011 34(1):6-10. [DOI:10.1179/107902610X12923394765733] [PMCID]

[4] Adams V. Neck injuries: I. Occipitoatlantal dislocation: A pathologic study of twelve traffic fatalities. Journal of Forensic Sciences. 1992; 37(2):556-64. [DOI:10.1520/JFS13263J] [PMID]

[5] Sekhon LH, Fehlings MG. Epidemiology, demographics, and pathophysiology of acute spinal cord injury. Spine. 2001; 26(24S):S2-S12. [DOI:10.1097/00007632-200112151-00002] [PMID]

[6] Wyndaele M, Wyndaele JJ. Incidence, prevalence and epidemiology of spinal cord injury: What learns a worldwide literature survey?. Spinal Cord. 2006; 44(9):523-29. [DOI:10.1038/sj.sc.3101893] [PMID]

[7] Rahimi Movaghar V, Sayyah MK, Akbari H, Khorramirouz R, Rasoul MR, Moradi Lakeh $M$, et al. Epidemiology of traumatic spinal cord injury in developing countries: A systematic review. Neuroepidemiology. 2013; 41(2):65-85. [DOI:10.1159/000350710] [PMID]

[8] Statistical Service of Cyprus (CYSTAT). Population and social conditions-health. Nicosia: CYSTAT; 2017

[9] Statistical Service of Cyprus (CYSTAT). Health and hospital statistics, 2005-2014, Series I, Report No. 26-35. Nicosia: CYSTAT; 2015.

[10] US National Center for Health Statistics. ICD-10- CM official guidelines for coding and reporting. FY 2017. Maryland: National Center for Health Statistics; 2017

[11] US National Center for Health Statistics. ICD-9-CM official guidelines for coding and reporting. Maryland: National Center for Health Statistics; 2011.

[12] Statistical Service of Cyprus (CYSTAT). Demographic report. 2005 2014; Series II, Report No. 43-51. Nicosia: CYSTAT.

[13] Dryden DM, Saunders LD, Jacobs P, Schopflocher DP, Rowe BH May LA, et al. Direct health care costs after traumatic spinal cord injury. Journal of Trauma and Acute Care Surgery. 2005; 59(2):443-9.

[14] Van den Berg ME, Castellote JM, Mahillo Fernandez I, de Pedro-Cuesta J. Incidence of spinal cord injury worldwide: A systematic review. Neuroepidemiology. 2010; 34(3):184-192. [DOI:10.1159/000279335] [PMID]

[15] Albert T, Ravaud JF. Rehabilitation of spinal cord injury in France: A nationwide multicenter study of incidence and regional disparities. Spinal Cord. 2005; 43(6):357-65. [DOI:10.1038/sj.sc.3101717] [PMID]

[16] Soopramanien A. Epidemiology of spinal injuries in Romania. Paraplegia. 1994; 32(11):715-22. [PMID]

[17] Pérez K, Novoa AM, Santamarina Rubio E, Narvaez Y, Arrufat V, Borrell $C$, et al. Incidence trends of traumatic spinal cord injury and traumatic brain injury in Spain, 2000-2009. Accident Analysis \& Prevention. 2012; 46:37-44. [DOI:10.1016/j.aap.2011.12.004] [PMID]

[18] Biering-Sørensen E, Pedersen V, Clausen S. Epidemiology of spina cord lesions in Denmark. Paraplegia. 1990; 28(2):105-18. [PMID] [DOI: 10.1038/sc.1990.13]

[19] Ahoniemi E, Alaranta H, Hokkinen EM, Valtonen K, Kautiainen H. Incidence of traumatic spinal cord injuries in Finland over a 30-year period. Spinal Cord. 2008; 46(12):781-4. [DOI:10.1038/sc.2008.53] [PMID]

[20] O'Connor RJ, Murray PC. Review of spinal cord injuries in Ireland Spinal Cord. 2006; 44(7):445-8. [DOI:10.1038/sj.sc.3101856] [PMID] 
[21] van Asbeck FW, Post MW, Pangalila RF. An epidemiological description of spinal cord injuries in The Netherlands in 1994. Spinal Cord. 2000; 38(7):420-4. [DOI:10.1038/sj.sc.3101003] [PMID]

[22] Karacan I, Koyuncu H, Pekel O, Sümbüloğlu G, Kırnap M, Dursun H, et al. Traumatic spinal cord injuries in Turkey: A nation-wide epidemiological study. Spinal Cord. 2000; 38(11):697-701. [DOI:10.1038/ sj.sc.3101064] [PMID]

[23] Sabre L, Pedai G, Rekand T, Asser T, Linnamägi U, Kõrv J. High incidence of traumatic spinal cord injury in Estonia. Spinal Cord. 2012; 50(10):755-9. [DOI:10.1038/sc.2012.54] [PMID]

[24] Ackery A, Tator C, Krassioukov A. A global perspective on spinal cord injury epidemiology. Journal of Neurotrauma. 2004; 21(10):1355-70. [DOI:10.1089/neu.2004.21.1355] [PMID]

[25] Hebert JS, Burnham RS. The effect of poly-trauma in persons with traumatic spine injury. A prospective database of spine fractures. Spine. 2000; 25(1):55-60. [DOI:10.1097/00007632-20000101000011] [PMID]

[26] lair JA, Patzkowski JC, Schoenfeld AJ, Cross Rivera JD, Grenier ES, Lehman RJ, et al. Spinal column injuries among Americans in the Global War on Terrorism. Journal of Bone and Joint Surgery. 2012; 94(18):1670-80. [DOI: 10.2106/JBJS.K.00502] [PMID]

[27] Burns SP, Goldstein B, Svircev J. Spinal cord injury rehabilitation. Walter Reed Army Medical Center Borden Institute, Lenhart MK, Pasquina CPF, Cooper RA, editors. Care of the Combat Amputee (Textbooks of Military Medicine). Virginia: United States Department of the Army; 2009.

[28] Macciocchi S, Seel RT, Thompson N, Byams R, Bowman B. Spinal cord injury and co-occurring traumatic brain injury: Assessment and incidence. Archives of Physical Medicine and Rehabilitation. 2008; 89(7):1350-7. [DOI:10.1016/j.apmr.2007.11.055] [PMID]

[29] Schwartz ED, Flanders AE. Spinal Trauma: Imaging, diagnosis and management. Philadelphia: Lippincott Williams and Wilkins; 2007. 
This Page Intentionally Left Blank 